\title{
New media and tobacco control
}

\author{
Becky Freeman
}

\section{Correspondence to}

Becky Freeman, School of Public Health, Sydney Medical School, The University of Sydney, 226A, Edward Ford Building A27, NSW 2006, Australia; becky.freeman@sydney.edu.au

Received 7 April 2011 Accepted 18 August 2011

\section{ABSTRACT}

Objective This paper reviews how the tobacco industry is promoting its products online and examines possible regulation models to limit exposure to this form of marketing. Opportunities to use new media to advance tobacco control are also discussed and future research possibilities are proposed.

Data sources Published articles and grey literature reports were identified through searches of the electronic databases, PUBMED and Google Scholar using a combination of the following search terms: tobacco or smoking and new media, online media, social media, internet media, Web 2.0, Facebook, YouTube and Twitter. Results A possible obstacle to fully realising the benefits of regulating tobacco marketing activities and effectively communicating tobacco control messages is the rapid evolution of the media landscape. New media also offer the tobacco industry a powerful and efficient channel for rapidly countering the denormalising strategies and policies of tobacco control. Evidence of tobacco promotion through online media is emerging, with YouTube being the most researched social media site in the tobacco control field.

Conclusions The explosive rise in Internet use and the shift to these new media being driven by consumer generated content through social platforms may mean that fresh approaches to regulating tobacco industry marketing are needed.

\section{INTRODUCTION}

Forms of media pervade nearly all corners of our lives. From the moment we first wake and turn on the radio, flick on the television, open a newspaper, or scroll though the feed from our favourite websites, the media capture our full attention and provide constant background noise. This pervasiveness continues through the rest of the day-television screens on public transport, billboards lining the streets, promoters giving away free entertainment papers, internet access on mobile phones - the list of opportunities to receive and share content is virtually endless. It would be surprising to find that this near-constant barrage of media messages did not have some effect on our beliefs, attitudes and behaviours, including about smoking.

A definitive review of nearly 2000 relevant references concludes that there is a causal relationship between tobacco promotion and increased tobacco use and that social marketing campaigns through the mass media are an effective way to curb smoking initiation and encourage smoking cessation. ${ }^{1}$ The depth of evidence that media influence tobacco use has propelled international action. Article 13 of the WHO Framework Convention on Tobacco Control (FCTC), ratified by 172 nations as of January 2011, ${ }^{2}$ translates this evidence into policy action by requiring all ratifying nations, barring any constitutional limitations, to adopt a total ban on tobacco advertising, promotion and sponsorship. The adopted guidelines for implementation of Article 13 of the treaty recognise that if only direct, traditional forms of tobacco advertising are banned, then the industry will simply shift resources to other, more covert promotional avenues. ${ }^{3}$

A possible obstacle to fully realising the benefits of regulating tobacco marketing activities and effectively communicating tobacco control messages is the rapid evolution of the media landscape. The explosive rise in internet use and the shift to 'new media' being driven by consumer generated content through social platforms may mean that fresh approaches to regulating tobacco industry marketing are needed. In recent years, the internet has changed dramatically from primarily an expert driven information source to an interactive, participatory and consumer driven medium, known commonly as 'Web 2.0' ${ }^{4}$ This change, coupled with the increased global reach of internet services, ${ }^{5}$ has the potential to create significant opportunities and challenges to implementing effective tobacco control.

\section{WHAT ARE NEW MEDIA?}

'New media' are the combination and convergence of computing and information technology, communications networks and digitised media and information content. ${ }^{6}$ The interlinking of these three key pillars has arisen due to the development and popularisation of the internet coupled with the accessibility of activities, products and services within the digital media sphere. In practical terms, the availability of relatively inexpensive smartphones (technology), combined with free, public wi-fi internet access (networks) and the launch of online video sharing websites such as YouTube (digitised content) have allowed consumers to view and to easily and rapidly create and share their own digital media. (Smartphones are those with advanced functions that are normally associated with a personal computer, such as email and internet access.) We can film an event on our phones, upload the clip to YouTube and then share the web link to the clip through our social networks, some of whom in turn may share that link through their respective networks.

New media have increased the accessibility of content, the amount of content and, perhaps most strikingly, the number of people who can create and share content. Unlike traditional mass media channels (television, newspaper, radio), which can be thought of as a 'one to many communication' platform, new media democratise mass media and create 'many to many communication' possibilities. 
Table 1 World internet use statistics and growth from 2000 to $2010^{9}$

\begin{tabular}{lcccl}
\hline World regions & $\begin{array}{l}\text { Internet users: } \\
\text { 31 December }\end{array}$ & $\begin{array}{l}\text { Internet users: } \\
\text { 30 June 2010 }\end{array}$ & $\begin{array}{l}\text { Growth } \\
\text { 2000-2010 (\%) }\end{array}$ & $\begin{array}{l}\text { Penetration } \\
\text { (\% of population) }\end{array}$ \\
\hline Africa & 4514400 & 110931700 & 2458 & 10.9 \\
Asia & 114304000 & 825094396 & 722 & 21.5 \\
Europe & 105096093 & 475069448 & 452 & 58.4 \\
Middle East & 3284800 & 63240946 & 1925 & 29.8 \\
North America & 108096800 & 266224500 & 246 & 77.4 \\
Latin America/Caribbean & 18068919 & 204689836 & 1133 & 34.5 \\
Oceania/Australia & 7620480 & 21263990 & 279 & 61.3 \\
\hline
\end{tabular}

Online social networking sites, such as Facebook and Renren (China's Facebook equivalent), typify how new media allow users to broadcast their own content and actively engage with other users. Of course, new media users can also simply view, read and listen to content and not necessarily engage with the content generation and interactive features.

\section{INCREASED ACCESSIBILITY OF THE INTERNET}

The development of and increased access to the internet is a key driver in the emergence of new media. While high-income countries generally have a greater percentage of internet users than low-income and middle-income countries, this is rapidly changing. (See table 1) The 'digital divide', described as 'the gap between individuals, households, businesses and geographic areas at different socioeconomic levels with regard to their opportunities to access information and communication technologies and to their use of the internet for a wide variety of activities', 8 while still a reality, particularly in Africa where internet access is only available to $10 \%$ of the population, is shrinking. ${ }^{5}$ Nigeria for example, has seen a nearly $22000 \%$ increase in internet access between 2000 and 2010, with approximately $30 \%$ of the population now accessing the web. ${ }^{9}$

\section{USER GENERATED CONTENT AND THE RISE OF ONLINE SOCIAL NETWORKING}

Web 2.0 has allowed the creation of an online environment where users share knowledge and information and build friendship or interest communities. ${ }^{4}$ This shift to a user-led environment is reflected in the list of global top 10 visited sites on the web. Of the 10 sites, 7 all reflect the Web 2.0 principles of interaction, social network connections and user generated content (the remaining 3 are search engines). ${ }^{10}$ See table 2 for the top 10 visited websites, calculated over a 3-month period to March 2011, by http://alexa.com, the web information company.

\section{WHAT IS KNOWN ABOUT TOBACCO CONTROL AND NEW MEDIA}

In his 2003 overview of the potential of the internet to promote and discourage tobacco use among youth, Ribisl noted that,

Table 2 Top 10 visited websites (global) $^{10}$

\begin{tabular}{lll}
\hline Rank & Site & Type \\
\hline 1 & Google & Search engine \\
2 & Facebook & Social networking \\
3 & YouTube & Video sharing \\
4 & Yahoo! & Web portal \\
5 & Windows Live & Search engine \\
6 & Blogger.com & Blog publishing \\
7 & Baidu.com & Search engine (China) \\
8 & Wikipedia & Encyclopaedia \\
9 & Twitter & Social networking and microblogging \\
10 & a0.COM & Web portal (China) \\
\hline
\end{tabular}

"websites and chat rooms are far more interactive than the venues in which cigarettes have traditionally been promoted, such as print advertising. That is, a viewer would probably spend far more time browsing and interacting with a prosmoking website than viewing a static cigarette advertisement in a magazine'. ${ }^{11}$ This is even more true today with the advent of Web 2.0 and the global appetite for new media, and yet despite this, there remains a scarcity of research on the promotional effects of tobacco content online.

Since the 2003 review article, the vast majority of research on tobacco control and the internet and new media has focused on developing smoking cessation tools and programmes. A 2010 Cochrane systematic review of internet-based interventions to help people quit smoking found that while overall the evidence was encouraging, research on long-term success rates was inadequate. ${ }^{12}$ The results suggest that some internet-based interventions can assist smoking cessation if the information is appropriately tailored to the users and frequent contact with users is ensured. However, trials did not show consistent effects.

The internet is an ideal platform for tobacco companies to pursue their increasingly curtailed promotional ambitions and to exploit the unprecedented opportunities that interactive cyberspace provides to marketers. ${ }^{13} \mathrm{New}$ media provide a continually evolving range of technologically innovative means for tobacco companies to keep favourable associations with smoking and particular brands in consumers' minds. New media also offer the tobacco industry a powerful and efficient channel for rapidly countering the denormalising strategies and policies of tobacco control. At the international tobacco industry event, Global Tobacco Networking Forum in Bangalore India in October 2010, a social media workshop and a plenary presentation by social media expert, Jason Falls, was scheduled and titled Social media in regulated markets. ${ }^{14}$

\section{TOBACCO SALES WEBSITES AS A DIRECT FORM OF PROMOTION}

The internet has been documented as a vehicle to potentially sell tobacco products, ${ }^{15-18}$ and sales websites are prolific and easily accessible through simple key word searches. These sites also serve as a direct form of tobacco promotion and advertising and can include forums for buyers (or supposed buyers) to leave product reviews. These reviews can also be a form of a promotion urging other buyers to purchase certain brands or try new products. Often these sites do not comply with national regulations that require health warnings to be shown alongside tobacco products or with restrictions that ban advertising at point of sale. The products sold on these sites are often less expensive than at retail outlets and buyers may not be compelled to pay the local taxes. While some counties have enacted laws to regulate sales in order minimise tax evasion and reduce direct sales to minors, they do not adequately address the promotional aspects of online sales. 


\section{PROMOTION OF TOBACCO PRODUCTS THROUGH ONLINE SOCIAL MEDIA}

A 2002 content analysis of pro-tobacco websites revealed that tobacco has a pervasive presence on the internet, especially on e-commerce sites and sites featuring hobbies, recreation and 'fetishes'. ${ }^{19}$ Only $11 \%$ of the sites examined contained health warnings. Many of the websites offered interactive site features that are potentially appealing to young people. A 2003 web content analysis found similar results in that youth could easily access pro-smoking lifestyle and culture content online. ${ }^{20}$ While there are still many niche pro-tobacco websites and blogs ${ }^{21} 22$ on the internet today, what is of greater concern is the presence of tobacco brand and products promotions on globally popular websites such as Facebook and YouTube.

Several instances of the tobacco industry embracing the principles of online engagement and connection with consumers have been documented. Thousands of US smokers helped to design a new pack for Camel cigarettes through an interactive website. ${ }^{23}$ British American Tobacco (BAT) employees internationally were found to be promoting BAT cigarette brands on Facebook. ${ }^{24}$ The cigarette rolling paper company Rizla hosts interactive and shareable games on its corporate website. ${ }^{25}$ The games are meant to reflect 'the brand's image as fun, interactive, individual, colourful and creative'. Adolescents are consistently exposed to tobacco content, such as pro-tobacco imagery and references to smoking in text, on the internet through their normal webpage viewing. ${ }^{26}$ Applications that promote tobacco use can also be downloaded onto mobile phones. ${ }^{27}$ For example, the iPhone application called the 'iShisha' is freely available on iTunes. ${ }^{28}$ The iShisha is a game that, as described by the app developers, 'you have the occasion to prepare your own shisha! Have fun during the single steps until your shisha is finished and enjoy the cozy background music. You can choose between four different tobacco tastes, each of them with its advantages and disadvantages. Figure out your favourite tobacco!'28

\section{RESEARCH ON YOUTUBE AND SMOKING}

YouTube is the most researched social media site in the tobacco control field. Since 2007, eight research papers have been published examining tobacco content on YouTube. Tobacco imagery is 'prolific and accessible' on the site $e^{29}$ and the dominance of pro-smoking over anti-smoking content has persisted over time. ${ }^{30}$ As YouTube continues to grow in total viewership and the number of videos on the site, so too has the number of tobacco-related videos increased. ${ }^{31}$ A 2009 study analysed YouTube search results for five leading non-Chinese cigarette brands worldwide. ${ }^{32}$ More than $70 \%$ of the tobacco brandrelated videos analysed in the study featured pro-tobacco content. Videos with pro-smoking content include product reviews, footage of tobacco sponsored events, images of young men and women smoking, smoking sexual fetish scenarios, magic tricks featuring cigarettes and vintage cigarette advertisements. BAT and Philip Morris USA both deny promoting their products on YouTube. ${ }^{33}$ While the body of research is unable to determine if the tobacco industry has posted any of this material there is evidence that distributors of the Swedish smokeless tobacco, snus, have posted promotional videos on the site. ${ }^{34}$ While the tobacco industry denies they post any content to these sites, they do not appear to have taken any active interest in removing it either. The industry could readily demand that any material that is copyrighted or makes use of tobacco industry trademark elements to generate income and traffic to a YouTube clip be removed immediately. ${ }^{35}$
Another study assessed the prevalence, accessibility and characteristics of smoking sexual fetish clips on YouTube. ${ }^{36}$ Smoking fetish videos are highly prevalent and accessible to adolescents on the website and feature sexually explicit smoking behaviour by young women. The authors called for tighter restrictions to ensure children cannot readily access this content. This type of content reinforces tobacco industry marketing messages that woman who smoke are attractive, youthful and empowered. ${ }^{37}$

Two of the YouTube studies specifically examined antismoking ${ }^{38}$ and quit smoking videos ${ }^{39}$ on the site. While there were a large number of anti-smoking videos on YouTube, the number was dwarfed by the number of pro-smoking videos. Of the anti-smoking videos analysed, those with the highest viewership also had high message sensation value (ie, included elements such music, quick edits, visuals) and were most likely to contain a threat appeal, such as developing mouth and lung cancer, or dying from smoking. ${ }^{38}$ The quit smoking video study measured the extent to which YouTube videos posted tagged as smoking cessation were about quitting smoking and whether or not these videos portrayed evidence-based practices. ${ }^{39}$

\section{REGULATING TOBACCO ADVERTISING ONLINE}

One of the most crucial issues that must be considered when regulating tobacco advertising online is whether the content is commercial in origin or is genuinely generated by tobacco consumers acting completely independently. The goal of tobacco advertising bans is not to prevent users from voicing their protobacco opinions but to prevent the tobacco industry from enticing new users and maintaining its current customer base. When money changes hands this distinction between personal and commercial speech is easily made, however when consumers are simply encouraged by the industry to engage in favourable online 'word of mouse' about tobacco products the distinction is less clear. Just as pro-smoking imagery in films has been shown to influence smoking uptake, ${ }^{40}$ pro-smoking content online, regardless of whether it is commercial or personal in origin, could equally influence users. In order for public health to counter these pro-smoking messages regulation of commercial messages and active engagement with online tools to counter pro-smoking messages are necessary.

There simply are no other media that facilitate the level of participation and engagement afforded by the internet. This core quality that makes the internet so attractive to so many participants is also what makes it difficult to regulate. Yet despite the freedom, flexibility and instant access enjoyed by many online users, most countries regulate content on the internet to some extent. A common justification for regulating the internet is to protect children from content that may be harmful, such as sexually explicit or violent material. ${ }^{41}$ Other general rationalisations for regulating internet content include protecting national security and political interests, safeguarding copyright and intellectual property, and improving computer security such as anti-spam and virus spreading laws. ${ }^{42}$

\section{Voluntary bans}

Working with popular online social networking sites to implement voluntary measures to eliminate tobacco advertising online is a possible solution. Most sites have policies about the type of advertising that is permissible and acceptable. Facebook for example, has a list of 20 types of advertisements that are prohibited on Facebook and the list includes tobacco products. ${ }^{43}$ However, this policy only strictly applies to advertising that appears as click through advertisements that display on the side 
of Facebook users' account pages, and not to popular fan pages and groups. Additionally, Google has a very similar policy banning the promotion of tobacco and cigarettes through Google advertisements. However, the policy has many loopholes ${ }^{44}$ and still allows tobacco sites to conduct advertising by creative use of key words such as promoting smoking accessories or smoking information.

\section{Filtering tobacco content}

Internet filtering is a common way of preventing people from accessing prohibited content. Filtering content by preventing internet service providers from allowing prohibited content to be accessed by users is the most common form of filtering. ${ }^{42}$ Filtering systems require that content on the internet be labelled so that the filtering system can assess whether the content is permissible or prohibited. This system does not necessarily prevent content creators for posting content, but does limit what other users can access. Filters are not foolproof however, and can be circumvented by determined and knowledgeable users who choose to access otherwise restricted content. Provided the content is labelled correctly and the filter is sound, this system can work to prevent children from accessing strictly adult only content. However, applying this model to tobacco control by simply requiring internet service providers to filter out all tobacco related content would inevitably result in vast amounts of anti-smoking material and non-commercial prosmoking content from being accessed. Or alternatively if the filter were not strict enough, only the most obvious forms of tobacco advertising (ie, tobacco sales or industry websites) would be censored. It is impractical for this type of system to be proactive, given the vast amounts of resources that would be required for monitoring, and as such would necessarily be driven by consumer complaints.

For example, in Australia the internet is classified as a broadcast medium and is subject to content regulation under the Broadcasting Services Act 1992. ${ }^{45}$ The Australian Communication and Media Authority (ACMA) is the body responsible for monitoring online content and will take action on material that is prohibited, or potentially prohibited. ${ }^{46}$ Prohibited content primarily includes highly sexually explicit content or material that does not have adequate access controls and is of a sexual nature, contains strong, realistic violence or deals with intense adult themes. Access controls are meant to ensure that internet users under the age 18 cannot access content rated $\mathrm{R}$ (restricted) and that users under age 15 cannot access content rated MA $15+$ (mature audience). The MA $15+$ rating, however only applies to services that provide material for a fee.

Hypothetically, if tobacco advertisements were included as part of this prohibited material, and if the prohibited content was hosted in, or provided from Australia, the ACMA would have the power to direct the content service provider to remove or prevent access to the content from their service. If the prohibited content is not hosted in, or provided from Australia, the ACMA could notify suppliers of approved internet filters to prevent Australian access, but could not demand that the material be removed from the internet.

Other commentators have suggested that if the most important purpose of regulating internet content is to protect children, then the responsibility needs to fall primarily to parents to prevent their children from accessing objectionable content. ${ }^{47}$ While parents and schools could update existing internet filter programmes to include tobacco content, again the same problems of over or under filtering exist. Additionally, countries that have implemented comprehensive tobacco advertising laws ban all forms of tobacco promotion from all audiences, not just marketing to children. As the internet is increasingly the means through which all audiences, children and adults alike, access news, ${ }^{48}$ information, entertainment ${ }^{49}$ and social networks, regulating tobacco advertising online must be a priority despite the challenges.

\section{Online content as part of a comprehensive tobacco advertising} ban

Many countries which have enacted tobacco advertising bans or restrictions state that they include internet-based advertising as part of laws banning all forms of tobacco advertising, promotion and sponsorship including content that is leaked across country borders. There is very little evidence on whether and how well these provisions are actually being enforced. Potential major problems with regulating internet content under advertising legislation are that not all tobacco content on the internet is commercial in origin ${ }^{50}$ and it would again be impossible to screen all tobacco content and assess whether it constitutes advertising under the definitions of comprehensive tobacco advertising prohibition legislation. ${ }^{3}$

Adequately defining and distinguishing between commercial and personal speech online will be necessary before any effective enforcement of legislation banning tobacco advertising is extended to the internet and Web 2.0 media. One of the main challenges here involves distinguishing pro-smoking or tobacco brand online posts that have been authored by citizens from those originating from clandestine tobacco companies and agents posing as consumers. In the former case, concerns eroding freedom of speech would arise. In the latter, problems will arise in establishing the author of commercially planned or commissioned posts. The global and borderless nature of the internet compounds this challenge and as such, cooperation among nations, particularly those that are parties to the WHO FCTC will be required.

Research on internet content regulation has failed to address the global nature of the online world, so international collaboration on a internet regulation is imperative. ${ }^{51}$ The WHO FCTC is an ideal mechanism for the exchange of information and best practices, analysis and provision of information on emerging technologies and knowledge to improve implementation of online tobacco advertising bans, particularly of content that reaches across country borders. ${ }^{52}$

\section{TOBACCO CONTROL ONLINE}

The borderless nature of the internet may also be viewed as an opportunity for tobacco control to be able to collaborate more freely and readily on online social marketing campaigns. It may also provide better opportunities for tobacco control experts around the word to assist local advocates. Responding to news media reports online can also extend to include global networks, strengthening the voices of local campaigners that can be drowned out by pro-tobacco forces.

There is much potential for tobacco control organisations to use and improve existing use of new media. In an exploratory study of the acceptability of receiving health messages through online social networking sites, users were receptive to receiving messages, with the most frequent and heaviest users of social networking sites being the most open to such communication. ${ }^{53}$ Determining the best way to engage with users and what sorts of messages would cut through the overwhelming amount of content online should become research priorities. For example, provocative and emotionally engaging clips could be posted on YouTube and then a link to the clip seeded through the Facebook, Twitter and blog postings of a group of supporters recruited to 
amplify and spread the message. ${ }^{54}$ Supporters could be readily recruited through non-governmental organisations and existing online communities. Or perhaps more radically, just as companies recruit brand ambassadors to influence consumers, tobacco control organisations could also engage with online users with large social networks to spread social marketing messages.

New media can also be a means to distribute tools and information that might assist in quitting smoking. 'Quit smoking' is a popular online search term ${ }^{55}$ and providing easy and free access to practical self-help materials is a cost effective way to help smokers quit. ${ }^{56}$ For example, while it appears there is a demand for quit smoking applications on smartphones, such as those available for the iPhone through the iTunes App store, the quality of these applications varies widely and overall is rated as very poor. ${ }^{58}$ Evidence-based quit smoking organisations partnered with experienced app developers could be well placed to create useful and inexpensive smartphone applications for smokers.

Using new media for tobacco control advocacy efforts have shown signs of promise. When American Idol pop singer, Kelly Clarkson, was bombarded with protest messages on her Facebook page, Twitter stream and blog as part of a campaign to stop the tobacco industry from sponsoring her concert in Indonesia in 2010, she decided to drop the sponsor. ${ }^{59}$ Online forums, such as social networking sites could be an ideal way to monitor and share tobacco industry activity globally and to mobilise tobacco control advocates with specific action requests (for an example, see: http://www.facebook.com/MonitoringTobaccoAdvertising).

\section{FUTURE RESEARCH}

It is easy to become excited about the possibilities the online sphere offers to tobacco control, and while it is true that virtually anyone can open a Facebook page, write a blog or start a Twitter account, this does not in any way guarantee that it will attract other online users or contribute to successful tobacco control. Just as traditional social marketing campaigns, community interventions, policy advocacy and research require coordinated approaches and dedicated resources to be successfully created and administered, so too do online efforts. A great advantage of online is that experimenting with communication techniques and messages is much less resource intense and potentially less risky than investing money in, for example, a new television campaign. Small-scale experiments assessing the most appropriate message content, format, delivery and online social networking site could be potential starting points for developing campaigns.

The research and development budget for social marketing campaigns is small compared to the funding required for broadcasting and publishing the campaign materials. The cost effectiveness of these intensive mass media campaigns has been well established, ${ }^{60}$ and it is now necessary to investigate if this same effectiveness can be realised through online campaigns. Online broadcasting through social networking sites is virtually free of cost, but effort and resources may need to be invested in fostering viewers and responding to viewer feedback. Researching what types of anti-smoking messages are the most appropriate online, and methodically analysing the processes and funding needed to attract and engage viewers, is essential. If inexpensive and effective campaigns can be delivered through online channels, this could be particularly beneficial to lowincome and middle-income countries that lack the resources needed for intensive and expensive mass media campaigns.

Continued research and monitoring of the online activities of the tobacco industry must also be a priority. This can be

\section{What this paper adds}

This paper provides an overview of how new media are relevant to tobacco control with a focus on online tobacco advertising and promotion.

- This paper discusses possible regulatory solutions to online tobacco marketing efforts.

achieved through joining online social networks, blogs, websites and following users, groups and companies that have connections to the tobacco industry. It is not at all necessary to do this in a clandestine or undercover manner, as much of the information is publicly available to anyone who cares to seek it out. Using Google Alerts to receive notification of new online content relevant to tobacco control is also a systematic and virtually effortless way to remain informed of online developments (Google Alerts are email updates of the latest relevant Google results (web, news, etc) based on your choice of query or topic. http://www.google.com/alerts). Additionally, it is important to conduct audience studies to determine who is being exposed to this type of content and what influence it has on attitudes and behaviour.

Assessing if online forums are also being used by the industry for lobbying and interference with the implementation of effective tobacco control is also important. Article 5.3 of the WHO FCTC requires signatory nations to protect public health policies with respect to tobacco control from commercial and other vested interests. ${ }^{61}$ Since 2009, Philip Morris International has launched a series of websites attacking and questioning the validity of tobacco control polices (see http://www.productdisplayban.com/Pages/Home.aspx and http://www.plain-packaging.com/Templates/HomePageTemplate.aspx). The latest site, launched by Philip Morris in Australia, is a portal to combat outdoor smoking bans, tax increases and plain packaging and features interactive tools for users to contact their Member of Parliament, to post messages, and to share the site with friends and contacts. Investigating whether these sites have any impact on political support for tobacco control efforts could be achieved by interviewing or surveying politicians and political staff about the number and type of messages they receive from these sites. Additionally, the message boards for the sites could be analysed to see how many commentators are engaging with the site and the type of feedback that is being received.

It is imperative that the tobacco control sector understand how the tobacco industry is and could be using new communications technology and endeavour to be equally skilled at using these same tools. Discouragingly, many public health experts are actually banned from accessing these media while at work and have received no training in how best to use these communication tools. ${ }^{62}$ Just as tobacco control stakeholders have learnt to use the traditional mass media to their full advantage, ${ }^{1}$ so too must this new media become part of standard practice for advancing tobacco control.

Acknowledgements The author thanks Simon Chapman for his helpful feedback on the initial draft, and the two anonymous reviewers and Jane Lewis for very helpful feedback on the original draft.

Funding This paper was supported by the National Health and Medical Research Council project grant 570869

Competing interests None declared.

Provenance and peer review Commissioned; externally peer reviewed. 


\section{REFERENCES}

1. National Cancer Institute. The Role of the Media in Promoting and Reducing Tobacco Use. Tobacco Control Monograph No. 19. Bethesda, MD: U.S. Department of Health and Human Services, National Institutes of Health, National Cancer Institute, 2008. NIH Pub. No. 07-6242. http://cancercontrol.cancer.gov/tcrb/ monographs/19/index.html (accessed 17 Jan 2010).

2. WHO Framework Convention on Tobacco Control. Parties to the WHO Framework Convention on Tobacco Control. 2011. http://www.who.int/fctc/ signatories_parties/en/index.html (accessed 17 Jan 2011).

3. Conference of the Parties. Guidelines for Implementation of Article 13 of the WHO Framework Convention on Tobacco Control (Tobacco advertising, promotion and sponsorship). 2008. http://www.who.int/fctc/guidelines/article_13.pdf (accessed 20 Jan 2011)

4. O'Reilly T. What is Web 2.0. 2005. http://oreilly.com/web2/archive/what-is-web-20. html (accessed 16 Feb 2011).

5. Internet World Stats. Internet Usage Statistics. The Internet Big Picture. World Internet Users and Population Stats. 2010. http://www.internetworldstats.com/stats. htm (accessed 16 Feb 2011).

6. Flew T. New Media: An Introduction. 3rd edn. Melbourne: Oxford University Press, 2008.

7. Tambini D. New Media and Democracy. New Media \& Society 1999;1:305-29.

8. International Telecommunication Union. Measuring the Information Society. 2010. http://www.itu.int//TU-D/ict/publications/idi/2010/Material/ MIS 2010 without annex 4-e.pdf (accessed 15 Feb 2011).

9. Internet World Stats. Top 20 Countries with the Highest Number of Internet Users. 2010. http://www.internetworldstats.com/top20.htm (accessed 3 Mar 2011).

10. Alexa. Top Sites. The Top 500 Sites on the Web. 2011. http://www.alexa.com/ topsites (accessed 4 Mar 2011).

11. RibisI KM. The potential of the internet as a medium to encourage and discourage youth tobacco use. Tob Control 2003:12(Suppl 1):i48-59.

12. Civljak M, Sheikh A, Stead LF, et al. Internet-based interventions for smoking cessation. Cochrane Database Syst Rev 2010;(9):CD007078. (accessed 7 Mar 2011).

13. Anderson SJ, Ling PM. "And they told two friends... and so on": RJ Reynolds' viral marketing of Eclipse and its potential to mislead the public. Tob Control 2008;17:222-9.

14. Global Tobacco Networking Forum. Look Who is Talking. 2010. http://www.gtnf2010.com/agenda.htm (accessed 11 Jul 2010).

15. Knowles JH Jr, Wanke KL, Kawachi I. Internet sales of tobacco: heading off the new E-pidemic. J Public Health Policy 2004;25:162-72.

16. RibisI KM, Kim AE, Williams RS. Web sites selling cigarettes: how many are there in the USA and what are their sales practices? Tob Control 2001:10:352-9.

17. RibisI KM, Kim AE, Williams RS. Are the sales practices of internet cigarette vendors good enough to prevent sales to minors? Am J Public Health 2002;92:940-1.

18. RibisI KM, Williams RS, Kim AE. Internet sales of cigarettes to minors. JAMA 2003;290:1356-9.

19. Hong $\mathbf{T}$, Cody MJ. Presence of pro-tobacco messages on the web. $J$ Health Commun 2002:7:273-307.

20. RibisI KM, Lee RE, Henriksen L, et al. A content analysis of Web sites promoting smoking culture and lifestyle. Health Educ Behav 2003;30:64-78.

21. Forest. Voice and Friend of the Smoker. 2011. http://www.forestonline.org/output/ home.aspx (accessed 7 Mar 2011)

22. Smoking Lobby. Advocating Smokers' Rights Worldwide. 2011. http://www. smokinglobby.com/ (accessed 7 Mar 2011).

23. Freeman B, Chapman S. Open source marketing: Camel cigarette brand marketing in the "Web 2.0" world. Tob Control 2009:18:212-17.

24. Freeman B, Chapman S. Undermining international tobacco advertising restrictions: British American Tobacco's profile on the social networking website Facebook. Tob Control 2010;19:e1.

25. Freeman B, Chapman S. Gone viral? Heard the buzz? A guide for public health practitioners and researchers on how Web 2.0 can subvert advertising restrictions and spread health information. J Epidemiol Commun Health 2008;62:778-82.

26. Jenssen B, Klein J, Salazar L, et al. Exposure to tobacco on the internet: content analysis of adolescents' internet use. Pediatrics 2009:124:e180-6.

27. Freeman B. Is an iPhone good for your health? BMJ Group Blogs 2010. http://blogs. bmj.com/bmj/2010/03/12/becky-freeman-is-an-iphone-good-for-your-health/ laccessed 7 Mar 2011).

28. Tent Games. iShisha. 2011. http://itunes.apple.com/us/app/ishisha/id346228466? $\mathrm{mt}=8$ (accessed 8 Aug 2011).

29. Freeman B, Chapman S. Is "YouTube" telling or selling you something? Tobacco content on the YouTube video-sharing website. Tob Control 2007;16:207-10.

30. Forsyth SR, Malone RE. "I'll be your cigarette-light me up and get on with it": examining smoking imagery on YouTube. Nicotine Tob Res 2010;12:810-16.

31. Elkin L, Thomson G. The extent of YouTube videos with smoking and smokefree words. N Z Med J 2010:123:93-4.

32. Elkin L, Thomson G, Wilson N. Connecting world youth with tobacco brands: YouTube and the internet policy vacuum on Web 2.0. Tob Control 2010;19:361-6.

33. Sinclair L. Tobacco firms deny YouTube adverts link. Sky News Online 26 August 2010. http://news.sky.com/skynews/Home/World-News/Tobacco-Companies-LikeMarlboro-And-LM-Deny-Getting-Round-Advertising-Bans-Through-YouTube/Article/ 201008415706397?lid=ARTICLE 15706397 TobaccoCompaniesLike MarlboroAndLMDenyGettingRoundAdvertising̈BansThroughYouTube\&lpos= searchresults (accessed 7 Mar 2011).
34. Seidenberg AB, Rees WW Connolly GN. Swedish match marketing on YouTube. Tob Control 2010;19:512-13.

35. YouTube. What is Copyright? 2011. http://www.youtube.com/t/copyright what is (accessed 8 Aug 2011).

36. Kim K, Paek H, Lynn J. A content analysis of smoking fetish videos on YouTube: regulatory implications for tobacco control. Health Commun 2010;25:97-106

37. Amos A, Haglund M. From social taboo to "torch of freedom": the marketing of cigarettes to women. Tob Control 2000:9:3-8.

38. Paek HJ, Kim K, Hove T. Content analysis of antismoking videos on YouTube: message sensation value, message appeals, and their relationships with viewer responses. Health Educ Res 2010;25:1085-99.

39. Backinger C, Pilsner A, Augustson E, et al. YouTube as a source of quitting smoking information. Tob Control 2011:20:119-22.

40. Heatherton TF, Sargent JD. Does watching smoking in movies promote teenage smoking? Curr Dir Psychol Sci 2009;18:63.

41. Broadcasting Standards Commission. Regulating the Internet. 1999. http://www. ofcom.org.uk/static/archive/bsc/pdfs/research/Update4Regulatingthelnternet.pdf (accessed 14 Mar 2011).

42. Dickerson NP. What makes the internet so special - and why, where, how, and by whom should its content be regulated. Hous L Rev 2009;46:61-102

43. Facebook. Facebook Advertising Guidelines. 5. Prohibited Content. 2011. http:// www.facebook.com/\#!/ad guidelines.php (accessed 17 Mar 2011).

44. Reynolds W. Google's tobacco advertising policy: Smoke and Mirrors. Seer Interactive. 2010. http://www.seerinteractive.com/blog/google\%E2\%80\%99stobacco-advertising-policy-smoke-and-mirrors/2010/01/07/ (accessed 17 Mar 2011)

45. Australian Government. Commonwealth Consolidated Acts. Broadcasting Services Act 1992. 2011. http://www.austlii.edu.au/au/legis/cth/consol act/bsa1992214/ (accessed 14 Mar 2011).

46. Australian Government, Australian Communication and Media Authority. Regulating Online Content. 2010. http://www.acma.gov.au/WEB/STANDARD/ $\mathrm{pc}=$ INT IND CONTENT ABOUT (accessed 14 Mar 2011).

47. Livingstone $\overline{\mathbf{S}}$, Bober $\overline{\mathrm{M}}$. Regulating the internet at home: contrasting the perspectives of parents and children. In: Willett R, ed. Digital Generations: Children Young People, and New Media. Mahwah, New Jersey: Lawrence Erlbaum Associates, 2006

48. Pew Research Center's Project for Excellence in Journalism. The state of the news media 2011. Key Findings 2011. http://giv.to/3KduGV (accessed 17 Mar 2011).

49. Phillips LE. eMarketer. The Video Viewing Audience: Trends for Marketers. 2011. http://www.emarketer.com/Reports/All/Emarketer_2000773.aspx (accessed $17 \mathrm{Ma}$ 2011)

50. Ang PH. Internet Society. Inet97 proceedings. How Countries Are Regulating Internet Content. 1997. http://www.isoc.org/inet97/proceedings/B1/B1 3.HTM laccessed 14 Mar 2011)

51. Yang KCC. A comparative study of Internet regulatory policies in the Greater China Region: Emerging regulatory models and issues in China, Hong-Kong SAR, and Taiwan. Telemat Inf 2007:24:30-40.

52. WHO. Measures that would contribute to the elimination of cross-border advertising promotion and sponsorship (decision FCTC/COP3(14)). Report of the Convention Secretariat. 2010. http://apps.who.int/gb/fctc/PDF/cop4/FCTC COP4 10-en.pdf (accessed 29 Oct 2010).

53. Uhrig J, Bann C, Williams $P$, et al. Social networking websites as a platform for disseminating social marketing interventions: an exploratory pilot study. SMO 2010;16:2-20

54. Carter 0, Donovan R, Jalleh G, et al. Using viral e-mails to distribute tobacco contro advertisements to young adults: an experimental investigation. $J$ Health Commun 2011;16:698-707.

55. Google Insights for Search. Web Search Interest: Quit Smoking. 2011. http:// www.google.com/insights/search/\#q=quit\%20smoking\&date=today\%2012 $\mathrm{mccmpt}=\mathrm{q}$ (accessed 17 Mar 2011)

56. Newman MG, Szkodny LE, Llera SJ, et al. A review of technology-assisted self-help and minimal contact therapies for drug and alcohol abuse and smoking addiction: Is human contact necessary for therapeutic efficacy? Clin Psychol Rev 2011;31:178-86

57. Lancaster T, Stead LF. Self-help interventions for smoking cessation. Cochrane Database Syst Rev 2005;(3):CD001118. http://www.mrw.interscience.wiley.com/ cochrane/clsysrev/articles/CD001118/frame.html

58. Abroms LC, Padmanabhan N, Thaweethai L, et al. iPhone apps for smoking Cessation: a content analysis. Am J Prev Med 2011:40:279-85.

59. The Associated Press. Kelly Clarkson dumps Indonesia tobacco sponsor. CBS News 2010. http://www.cbsnews.com/stories/2010/04/22/entertainment/ main6421011.shtml (accessed 14 Mar 2011).

60. Hurley SF, Matthews JP. Cost-effectiveness of the Australian National Tobacco Campaign. Tob Control 2008;17:379-84.

61. Conference of the Parties. Guidelines for implementation of Article 5.3 of the WHO Framework Convention on Tobacco Control on the protection of public health policies with respect to tobacco control from commercial and other vested interests of the tobacco industry. 2008. http://www.who.int/fctc/guidelines/article 5 3.pdf (accessed 24 Mar 2011).

62. Freeman B. The Conversation. Ouit-smoking Texts Send Clear Message to Outdated Health Promoters. 2011. http://theconversation.edu.au/quit-smoking-texts-sendclear-message-to-outdated-health-promoters-2093 (accessed 2 Jul 2011) 